\title{
PEMANFAATAN DIGITAL LIBRARY PADA PERPUSTAKAAN KAMPUNG PENDIDIKAN DESA KUAJANG KABUPATEN POLEWALI MANDAR
}

\author{
Safriansyah ${ }^{1}$, Nur Hafsah Yunus MS², Arifin TAHIR ${ }^{3}$, Syarli4, Wahyuddin ${ }^{5}$ \\ FHISIP Universitas Terbuka \\ Email: safri@ecampus.ut.ac.id
}

\begin{abstract}
The lack of interest in reading nowadays is one of the factors in the decline of the nation's regeneration that loves literacy. The Education Village Library Group of Kuajang Village, Binuang District is one of the literacy movements established in Kuajang Village. This library is part of a project of teenagers and hamlet residents to build a literacy village to feel the equal distribution of education without having to abandon the value of local wisdom. In addition, it also aims to increase public interest in reading through the development of an appropriate technology as a solution, namely the digital library. The method of implementation is in accordance with the planning stages that have been prepared, namely the stages of activities that begin with the coordination and analysis of needs (Phase I), digital library application design (Phase II), application integration in the framework model (Phase III), and the use of systems in the field (Stage IV). The results show that the application development uses the OPAC (Online Public Access Catalog) model that can facilitate the user in the process of searching for books and the initial display of the digital library system in the form of a catalog. To optimize the use and utilization of this application, training is carried out to users and managers of the Education Village Library Group. In addition, periodic monitoring and assistance will be carried out to ensure the use of this system can be operated and the benefits are felt by the community.
\end{abstract}

Key Words: Digital Library, Literacy, Kuajang Village.

\begin{abstract}
ABSTRAK
Rendahnya minat baca masyarakat saat ini menjadi salah satu faktor kemorosotan regenerasi bangsa yang cinta terhadap literasi. Kelompok Perpustakaan Kampung Pendidikan Desa Kuajang Kecamatan Binuang merupakan salah satu gerakan literasi yang didirikan di Desa Kuajang. Perpustakaan ini merupakan bagian dari proyek remaja dan warga dusun untuk membangun sebuah kampung literasi untuk merasakan pemerataan pendidikan tanpa harus meninggalkan nilai kearifan lokal. Selain itu, bertujuan juga untuk meningkatkan minat baca masyarakat melalui pengembangan suatu teknologi yang tepat guna sebagai solusi, yakni digital library. Adapun metode pelaksanaan sesuai dengan tahapan perencanaan yang telah disusun, yaitu tahapan kegiatan yang diawali dengan koordinasi dan analisis kebutuhan (Tahap I), perancangan aplikasi digital library (Tahap II), integrasi aplikasi pada model framework (Tahap III), dan penggunaan sistem di lapangan (Tahap IV). Hasilnya menunjukkan bahwa pengembangan aplikasi menggunakan model OPAC (Online Public Access Catalogue) yang dapat memudahkan pengguna dalam proses pencarian buku dan tampilan awal dari sistem digital library dalam bentuk katalog. Untuk optimalisasi penggunaan dan pemanfaatan aplikasi ini maka dilakukan pelatihan kepada pengguna dan pengelola Kelompok Perpustakaan Kampung Pendidikan. Selain itu, akan dilakukan pemantauan dan pendampingan berkala untuk memastikan penggunaan sistem ini mampu dioperasikan dan dirasakan manfaatnya oleh masyarakat.
\end{abstract}

Kata Kunci: Digital Library, Literasi, Desa Kuajang. 


\section{PENDAHULUAN}

Rendahnya minat baca masyarakat saat ini menjadi salah satu faktor kemorosotan regenerasi bangsa yang cinta terhadap literasi. Tidak bisa pungkiri bahwa kelompok literasi Kampung Pendidikan ini sangat bermanfaat bagi masyarakat apalagi bagi pelajar dan mahasiswa yang notabene ingin memperoleh informasi mengenai kebudayaan Mandar, memiliki tugas sekolah, riset, dan informasi lainnya. Banyaknya jumlah buku atau bahan bacaan di perpustakaan ini menjadi salah satu perpustakaan yang paling ramai dikunjungi oleh masyarakat baik pelajar maupun masyarakat umum. Hal ini yang menjadi daya pikat bagi Kelompok Literasi Kampung Pendidikan Desa Kuajang Kecamatan Binuang.

Namun, karena jarak tempuhnya yang terbilang jauh dari pusat kota, sehingga ini juga menjadi kendala bagi masyarakat umum atau pelajar yang ingin mengunjungi perpustakaan tersebut. Sementara itu, belum ada aplikasi atau teknologi yang dianggap mampu memberi daya tarik bagi pengunjung guna lebih meningkatkan minat baca buku bagi masyarakat, sehingga perlu diadakan suatu terobosan baru untuk kembali menggairahkan semangat literasi bagi masyarakat. Apalagi saat ini, masyarakat baik pelajar maupun masyarakat umum sangat bergantung pada telepon pintar karena jaringan internet sudah merambah ke pelosok desa dalam hal ini, kondisi jaringan internet di Desa Kuajang sudah sangat mudah diakses. Kurangnya pemahaman terhadap penggunaan smartphone menjadikan masyarakat hanya sebatas menggunakan, bukan memanfaatkan teknologi. Hal ini pulalah yang menjadi salah satu cikal bakal muncul kelompok pemuda di Desa Kaujang.

Kelompok Perpustakaan Kampung Pendidikan Desa Kuajang Kecamatan Binuang merupakan salah satu gerakan literasi yang pada akhirnya terjadi di Desa Kuajang. Pemuda di Dusun Lemo Tua Desa Kuajang, Kecamatan Binuang, Kabupaten Polewali Mandar Provinsi Sulawesi Barat mendirikan perpustakaan kampung pendidikan yang di mulai pada akhir Desember 2017 lalu. Perpustakaan ini merupakan bagian dari proyek remaja dan warga dusun untuk membangun sebuah kampung daerah terdepan, terluar, dan tertinggal (3T) untuk merasakan pemerataan pendidikan tanpa harus meninggalkan nilai kearifan lokal. Upaya peningkatan minat baca masyarakat di Desa Kuajang Kecamatan Binuang dan masyarakat Polewali Mandar pada umumnya perlu mendapat perhatian serius. Sebagai salah satu daerah 3T, penting untuk mengembangkan suatu iptek yang tepat sebagai solusi.

Tantangan perpustakaan di era digital semakin banyak. Perpustakaan kini tak lagi hanya bangga dengan banyaknya tumpukan koleksi di raknya. Karena perilaku pencarian informasi pemakai yang dilayani juga mengalami perubahan seiring dengan kemajuan teknologi informasi. Agar perpustakaan tetap eksis sesuai dengan kemajuan teknologi, maka harus mampu mengembangkan diri. Salah satunya adalah dengan membangun perpustakaan digital. Untuk membangun digital library, diperlukan pertimbangan dan perencanaan yang matang, agar nantinya benar-benar bermanfaat bagi pemakai. Digital library adalah sebuah sistem yang memiliki berbagai layanan dan objek informasi yang mendukung akses objek informasi tersebut melalui perangkat digital. Layanan ini diharapkan dapat mempermudah pencarian informasi di dalam koleksi obyek informasi seperti dokumen, gambar dan database dalam format digital dengan cepat, tepat, dan akurat (Siswanto, 2008).

Munculnya Digital Library memiliki keunggulan dalam kecepatan pengaksesan karena berorientasi ke data digital dan media jaringan komputer atau internet dimana pada umumnya dibangun menjadi sebuah aplikasi berbasis web, dimana pada pembangunannya banyak developer memanfaatkan framework dalam membangun kodingnya. Salah satu framework yang sering digunakan adalah Codelgniter. Penggunaan framework dalam berkoding dirasa lebih efisien dalam pembangunan sebuah aplikasi yang berskala besar, sebagaimana yang dikemukakan Rahayu (2016) bahwa framework memungkinkan kita membangun aplikasi dengan lebih cepat karena sebagai developer kita akan lebih memfokuskan pada pokok permasalahan sedangkan hal-hal penunjang lainnya seperti koneksi database, form validation, GUI, dan security umumnya telah disediakan oleh framework. 
Disamping itu dengan aturan-aturan yang jelas dan harus dipatuhi, aplikasi kita lebih solid, more readable, dan kolabarasi dalam tim dapat lebih mudah dilaksanakan.

Salah satu framework yang sering digunakan oleh Pengembangan aplikasi menggunakan model OPAC (Online Public Access Catalogue) yang dapat memudah pengguna dalam proses pencarian buku dan tampilan awal dari sistem digital Library dalam bentuk katalog. Menurut Wicaksono (2007), OPAC merupakan katalog yang berisikan cantuman bibliografi dari koleksi satu atau beberapa perpustakaan, disimpan pada magnetic disk atau media rekam lainnya, dan dibuat secara online kepada pengguna. Selain itu, Yulianton, dkk (2015) menyatakan bahwa OPAC adalah suatu sistem temu balik informasi, dengan satu sisi masukan (input) yang menggabungkan pembuatan file yang tercantum dan indeks. Pengguna dapat menggunakan OPAC untuk menjawab permintaan atau pertanyaan tertentu dan menjadi salah satu sarana atau alat bantu untuk menelusuri informasi di perpustakaan yang menggunakan sistem komputer yang terpasang jaringan LAN (Local Area Network).

Jadi secara umum, OPAC adalah suatu sistem temu balik informasi berbasis komputer yang digunakan oleh pengguna untuk menelusuri koleksi suatu perpustakaan atau unit informasi lainnya.

\section{METODE PELAKSANAAN}

Tahapan metode pelaksanaan secara garis besar dijelaskan sebagai berikut :

a. Tahap I, berupa Koordinasi dan Analisis kebutuhan Usulan yang terdiri dari :

i. Persiapan dan koordinasi, pada tahapan ini dilakukan persiapan kebutuhan untuk kemitraan dan koordinasi pada mitra dalam mengimplementasikan kerjasama.

ii. Analisis system yang diusulkan, pada tahapan ini dibuat model operasional sistem yang dijalankan pada sistem perpustakaan digital.

b. Tahap II, berupa Perancangan Aplikasi Perpustakaan Digital yang terdiri dari :

i. Perancangan User Interface Berbasis Website, pada tahapan ini, mulai dilakukan perencanaan model User Interface sesuai dengan kebutuhan sistem yang dirancang, terlihat pada gambar 3.1.

ii. Web Hosting, pada tahapan ini, hasil rancangan sistem perpustakaan digital yang telah dibuat selanjutnya di hosting pada server untuk proses lauching Aplikasi.

iii. Web Advertising, pada tahapan ini, dilakukan promosi atau publikasi tentang keberadaan sistem perpustakaan digital melalui berbagai macam media.

c. Tahap III, berupa Integrasi Sistem pada Model Framework Web yang terdiri dari :

i. Framework Web, pada tahapan ini dilakukan penerapan Framework Web untuk menguji performance aplikasi perpustakaan digital dalam melakukan akses searching buku dan peminjaman.

ii. Optimasi Model Layanan, pada tahapan ini, dilakukan optimasi website dengan mengukur tingkat kemudahan dalam penggunaan atau user friendly.

iii. Simulasi Penerapan, pada tahapan ini, dilakukan simulasi penggunaan aplikasi untuk menguji kehandalan aplikasi berbasis web yang telah dibangun.

d. Tahap IV, berupa penerapan sistem aplikasi digital library di Lapangan yang terdiri dari :

i. Pada sistem digital library masyarakat dapat mengakses aplikasi tersebut dan dapat melihat buku-buku yang terdapat dalam sistem. Akan tetapi, untuk melakukan proses peminjaman buku, masyarakat harus terdaftar sebagai anggota. Prosedur pendaftaran sebagai anggota juga terdapat pada sistem yaitu menu registrasi, pada menu ini masyarakat akan melakukan registrasi dengan memasukkan identitas sesuai dengan data kependudukan, pada form registrasi setiap masyarakat yang mendaftar wajib memasukkan Nomor Induk Kependudukan (NIK) yang dijadikan sebagai validasi keakuratan data pendaftar. Bagi masyarakat yang telah terdaftar sebagai anggota, akan memiliki akun yang digunakan untuk mengakses beberapa menu yang tersedia pada sistem seperti edit profil, edit akun, 
informasi stok buku, request judul buku, peminjaman dan pengembalian. Login yang dilakukan oleh anggota menggunakan NIK sebagai username dan password yang merupakan akun standar pada sistem dan untuk keamanan data, anggota dapat melakukan perubahan username maupun password pada menu edit akun. Pada proses peminjaman, sistem membatasi jumlah buku yang dapat dipinjam oleh anggota yaitu sebanyak tiga buku dengan batas waktu peminjaman selama 1 minggu, peminjaman buku dalam bentuk hardcopy melalui sistem hanya dalam bentuk reservasi awal, agar admin mengubah status buku pada sistem dan dalam proses reservasi terdapat batasan waktu, jika waktu reservasi telah habis kemudian anggota tidak melakukan peminjaman secara langsung dengan menemui petugas perpustakaan, maka sistem akan mengubah status buku tersebut untuk dapat dipinjam oleh anggota yang lain. Dan untuk buku yang tersedia dalam bentuk digital, anggota dapat mengunduhnya setelah melakukan proses peminjaman dan buku digital yang telah diunduh menjadi milik anggota dan tidak terdapat proses pengembalian buku digital pada sistem.

ii. Pada sistem akan tersaji laporan dalam beberapa kategori yaitu laporan jumlah anggota perpustakaan, laporan jumlah buku berdasarkan kategori, laporan judul buku yang dipinjam diurut berdasarkan jumlah peminjamannya sehingga dapat diketahui judul buku yang paling diminati oleh anggota, jumlah buku yang diunduh diurut berdasarkan jumlah unduhnya, laporan peminjaman dan laporan pengembalian. Adapun skema tahapan pelaksanaan dapat dilihat pada Gambar 1 berikut.

iii.

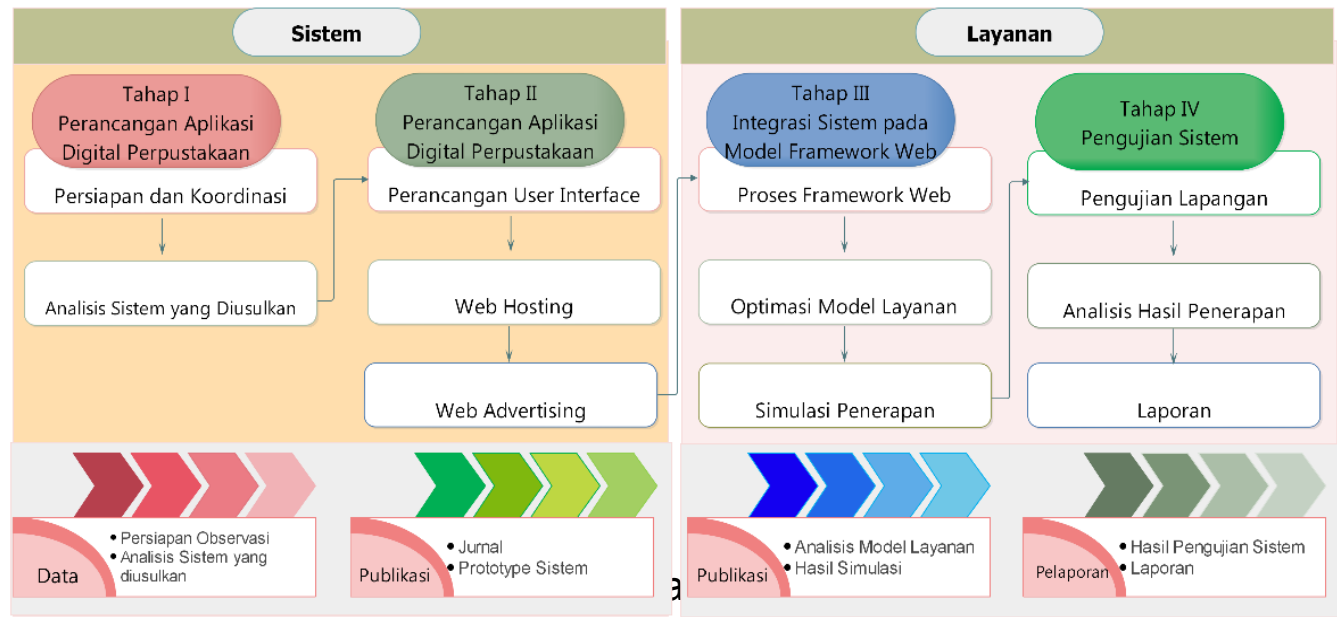

\section{HASIL DAN PEMBAHASAN}

\section{Perancangan Sistem}

Perancangan sistem digital library dilakukan sebagaimana target luaran yang diharapkan dari kegiatan pengabdian kepada masyarakat pada Kelompok Perpustakaan Kampung Pendidikan Desa Kuajang Kecamatan Binuang Polewali Mandar. Pengembangan aplikasi menggunakan model OPAC (Online Public Access Catalogue) yang dapat memudahkan pengguna dalam proses pencarian buku dan tampilan awal dari sistem digital Library dalam bentuk katalog. Untuk optimalisasi penggunaan aplikasi dilakukan pelatihan kepada admin yang ditunjuk oleh pengelola Kelompok Perpustakaan Kampung Pendidikan selai itu tim akan melakukan pendampingan berkala agar pemahaman admin dalam penggunaan sistem mumpuni dalam pengoperasian sistem (Fatimah,F et al, 2019). 


\section{Homepage sistem digital library}

Halaman utama bertujuan untuk menampilkan data-data buku yang dapat dilihat oleh pengguna. Pengguna yang tidak terdaftar sebagai anggota, maka tidak dapat melakukan peminjaman buku pada sistem sehingga wajib melakukan registrasi melalui sistem dan hasil dari proses registrasi tersebut maka pengguna akan mendapatkan username dan password untuk dapat melakukan login sistem. Halaman utama sistem ditunjukkan pada Gambar 2.

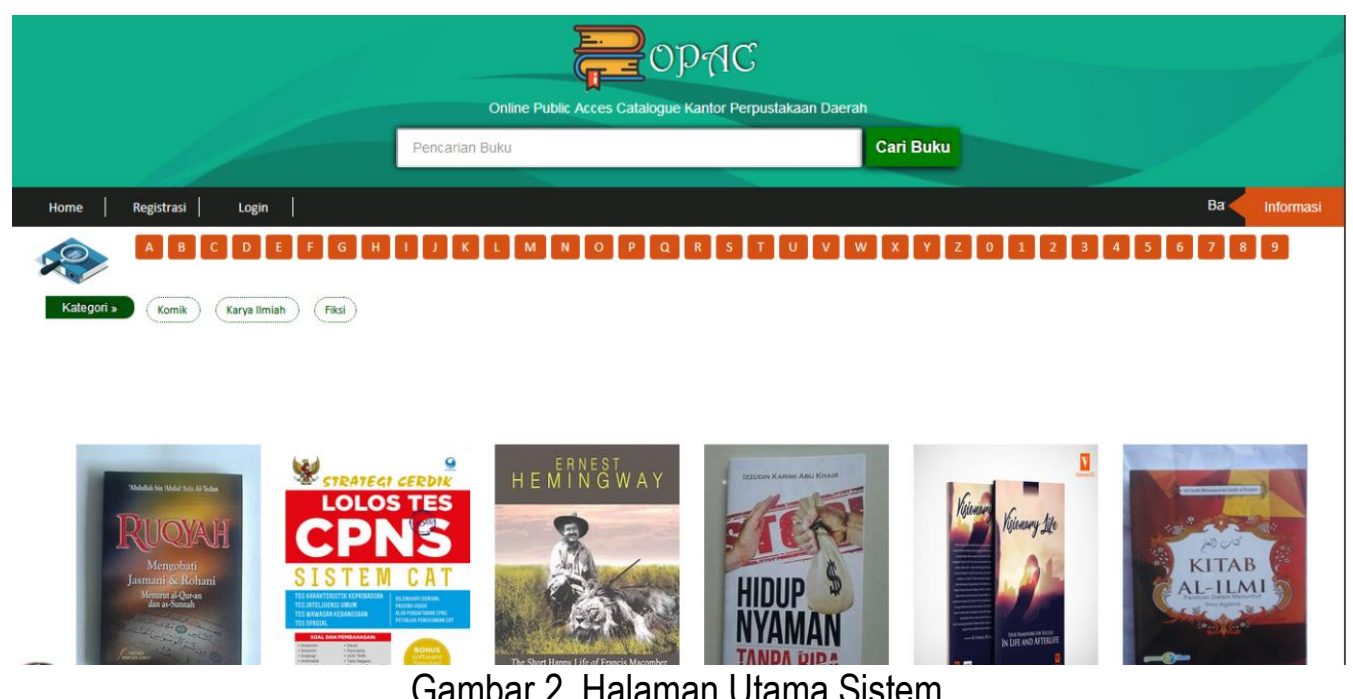

\section{a. Halaman Registrasi}

Selanjutnya dalam proses registrasi, pengguna akan melakukan pengisian biodata pada form registrasi berupa nama, jenis kelamin, alamat, jenjang pendidikan, nomor telpon, email aktif, password, dan pas foto sebagai identitas anggota. Form registrasi ditunjukkan pada Gambar 3.

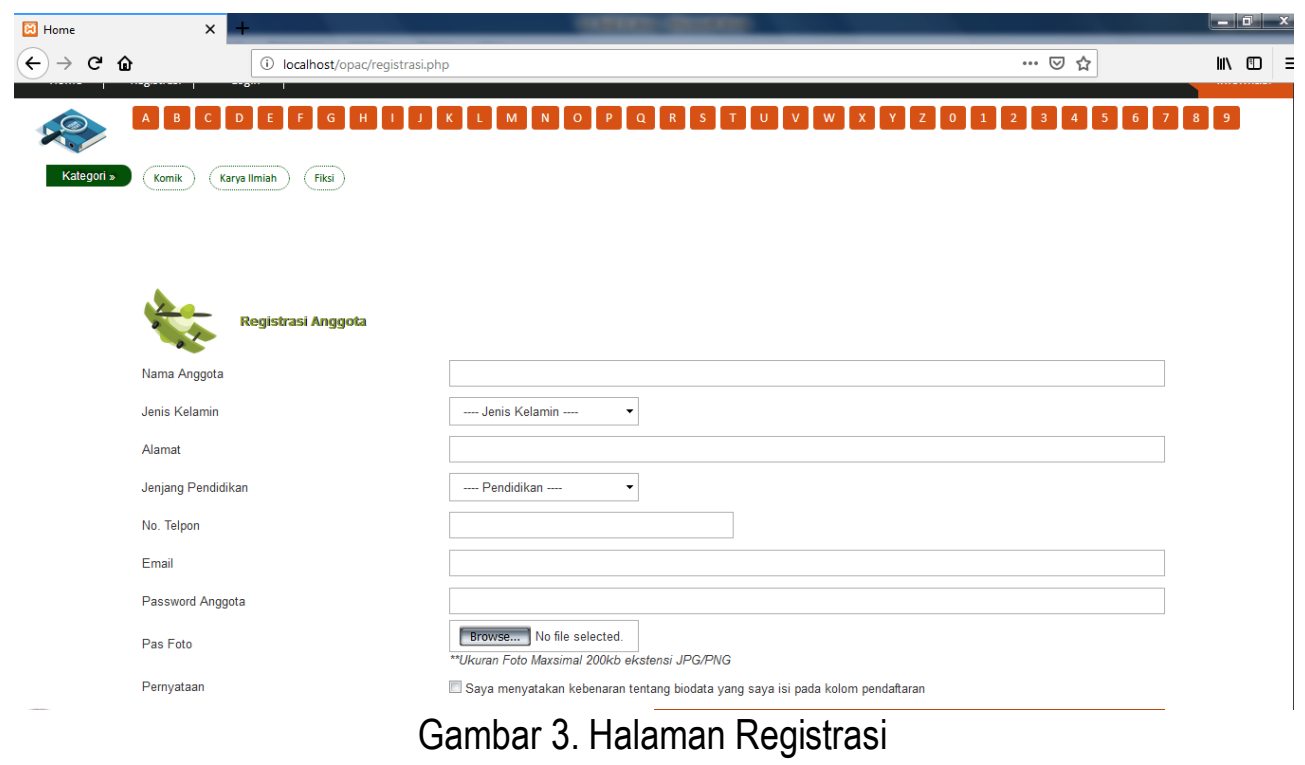

\section{b. Halaman Login}

Selanjutnya pada proses login terdapat 2 level akses, yaitu anggota dan admin masingmasing level memiliki batasan dalam mengakses fasilitas pada sistem. (1) Anggota, level ini pengguna hanya dapat melihat buku dan melalukan peminjaman buku serta dapat melihat status buku; (2) Admin, level ini merupakan pengelola dari sistem dimana proses yang dilakukan seperti pengelola data buku, 
pengelola data anggota dan dapat memantau transaksi pemnjaman maupun pengembalian buku pada sistem. Halaman login ditunjukkan pada Gambar 4.

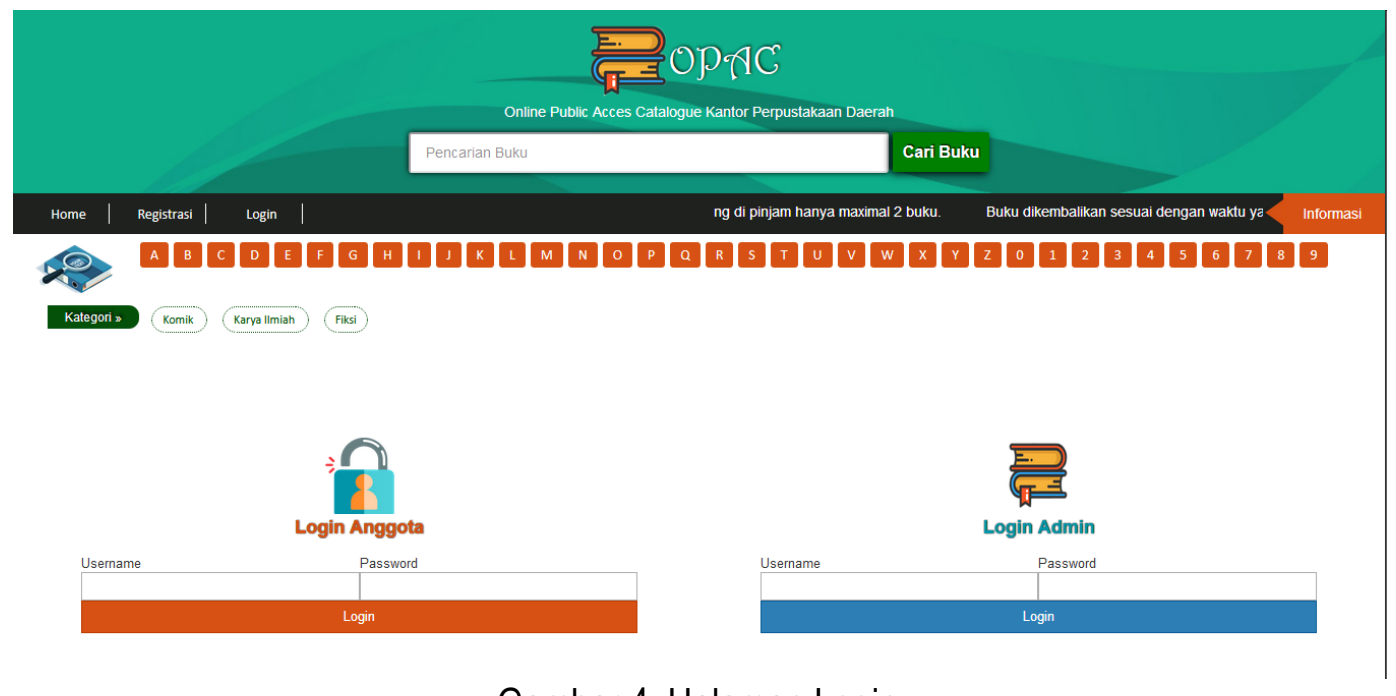

Gambar 4. Halaman Login

\section{c. Halaman Dashboard Admin}

Pada halaman ini akan menampilakan rekap data yang ada pada sistem berupa jumlah anggota, jumlah buku, data antrian peminjaman buku, dan peminjaman buku. Halaman dashboard admin ditunjukkan pada Gambar 5.

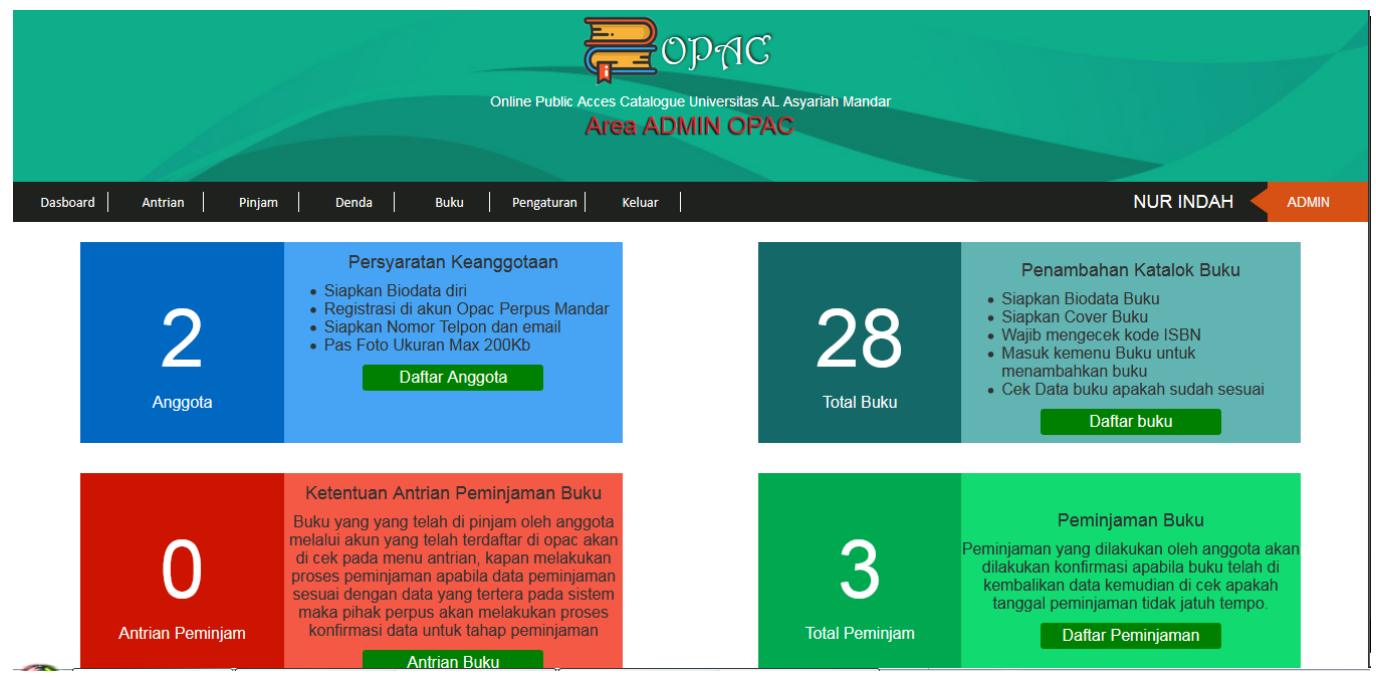

Gambar 5. Halaman Dashboard Admin

\section{Pelatihan Kelompok Sasaran}

Kegiatan pelatihan pada kelompok sasaran ini dimaksudkan untuk meningkatkan pengetahuan penerapan teknologi di masyarakat, penerapan teknologi dalam berbagai aspek dapat membantu masyarakat untuk memudahkan dalam menyelesaikan pekerjaan dan pengelolaan data terkomputerisasi sehingga keamanan dan pengarsipan datanya jauh lebih baik. Pelatihan ini terbagi dalam 2 (dua) kegiatan yaitu Pelatihan Pengoperasian aplikasi pada level pengguna dan admin. 


\section{SIMPULAN}

Berdasarkan hasil dan pembahasan di atas dapat disimpulkan bahwa penerapan dan penggunaan aplikasi digital library pada Perpustakaan Kampung Pendidikan Desa Kuajang Kabupaten Polewali Mandar dapat dijalankan sesuai alur sistem. Antusias masyarakat dan pengelola perpustakaan sangat baik dalam pemanfaatan aplikasi digital library apalagi setelah dilaksanakan pelatihan penggunaan aplikasi digital library bagi pengelola dan pengguna. Bagi pengelola perpustakaan sangat membantu dalam meningkatkan pelayanan kepada pengguna perpustakaan, sedangkan bagi pengguna sangat efektif dan efisien dalam mencari buku atau referensi yang dibutuhkan.

Oleh karena itu, dengan adanya digital library sangat mempengaruhi minat baca masyarakat pada Perpustakaan Kampung Pendidikan, hal ini dapat dilihat pada saat peluncuran perdana aplikasi dan pelaksanaan pelatihan penggunaan aplikasi.

\section{REFERENSI}

Arms, William. 2000. Digital Library. MIT Press.

Dwiyantoro. 2017. "Recal dan Precision OPAC Perpustakaan Universitas Gadjah Mada". Yogyakarta : UGM.

FATIMAH, F., YUSRAFIDDIN, Y., MUHAMMADI, M., DELFI, R., \& GUSTI, Z. (2019). INFORMATION LITERACY IN EARLY CHILDHOOD EDUCATION. DISEMINASI: Jurnal Pengabdian kepada Masyarakat, 1(2), 99-106.

Pendit, Putu Laxman (Ed). 2007. Perpustakaan digital: Sebuah Impian dan Kerja Bersama. Jakarta: Sagung Seto.

Rahayu, Sri Harlina. 2016. Strategi Promosi Layanan Perpustakaan di Badan Penelitian Pengembangan Perpustakaan Daerah Bulukumba. Skripsi.

Siswanto. 2008. Manajemen Perpustakaan Digital. Jakarta: Afifa Pustaka.

Wicaksono, Dony Prisma, 2017. "Efektifitas Sistem Temu Kembali Informasi pada OPAC Perpustakaan Fakultas IImu Sosial Universitas Negeri Yogyakarta".

Yulianton H., Andreas F., Susanto dan Mulyani, Sri. 2015." Rancang bangun Onlain Public acces Catalogue(OPAC) Pada perpustakaan Universitas Stikubank menggunakan Bootstrap". 